\title{
Leptina como marcadora do dimorfismo sexual em recém-nascidos
}

\author{
Leptin as a marker of sexual dimorphism in newborn infants \\ Inês M. C. G. Pardo', Bruno Geloneze², Marcos A. Tambascia², \\ José L. Pereira ${ }^{3}$, Antonio A. Barros Filho ${ }^{4}$
}

\section{Resumo}

Objetivo: Avaliar os níveis de leptina do cordão umbilical em recém-nascidos adequados para a idade gestacional conforme sexo, peso, comprimento e índice ponderal de nascimento.

Método: Estudo tipo transversal, envolvendo 132 recém-nascidos adequados para idade gestacional (68 do sexo feminino, 64 do sexo masculino), com idade gestacional de 35-42 semanas. Os dados foram obtidos mediante entrevista com as mães na maternidade, pelo estudo antropométrico dos recém-nascidos e pela dosagem de leptina, estradiol e testosterona no cordão umbilical por meio da coleta imediata após o parto.

Resultados: Os recém-nascidos do sexo feminino apresentaram níveis de leptina significativamente maiores que os do sexo masculino $(8,34 \pm 0,65 \mathrm{ng} / \mathrm{ml}$ versus $6,06 \pm 0,71 \mathrm{ng} / \mathrm{ml} ; \mathrm{p}=0,000)$. Os níveis de estradiol e testosterona não variaram conforme o sexo. A leptina se correlacionou positivamente com idade gestacional $(r=0,394, p<0,01)$, peso $(r=0,466, p<0,01)$, comprimento $(r=0,335, p<0,01)$ e índice ponderal $(r=0,326, p<0,01)$ dos recém-nascidos.

Conclusões: A leptina do cordão umbilical se correlaciona positivamente com idade gestacional, peso, comprimento e índice ponderal do recém-nascido, sugerindo sua participação no processo de crescimento neonatal. Além disso, os recém-nascidos do sexo feminino têm níveis séricos de leptina maiores que os do sexo masculino, sugerindo que o dimorfismo sexual relacionado à composição corporal já possa existir em recém-nascidos.

J Pediatr (Rio J). 2004;80(4):305-8: Leptina, recém-nascido, peso de nascimento, crescimento.

\section{Introdução}

A leptina (palavra grega leptos, que significa "magro") é uma proteína de $16 \mathrm{kDa}$ sintetizada pelos adipócitos que foi recentemente descoberta por intermédio de estudos genéticos realizados por Zhang et al. ${ }^{1}$. Desde então, uma série de estudos vêm sendo desenvolvidos no sentido de esclarecer seu papel na fisiologia humana.

1. Doutoranda do Curso de Pós-Graduação em Pediatria, Universidade Estadual de Campinas (UNICAMP), Campinas, SP.

2. Doutor; Professor da Disciplina de Endocrinologia e Metabologia, Departamento de Clínica Médica, Faculdade de Ciências Médicas, UNICAMP, Campinas, SP

3. Chefe da Disciplina de Neonatologia, Departamento de Pediatria, Pontifícia Universidade Católica de São Paulo (PUCSP), São Paulo, SP.

4. Doutor; Professor, Departamento de Pediatria, Faculdade de Ciências Médicas, UNICAMP, Campinas, SP.

Fonte financiadora: Fundação de Amparo à Pesquisa do Estado de São Paulo - FAPESP.

Artigo submetido em 17.12.03, aceito em 26.04.04.

\begin{abstract}
Objective: To determine cord blood leptin levels in newborns appropriate for gestational age, according to gender, birth weight, birth height and ponderal index.

Methods: A cross-sectional study was carried out with 132 term newborns appropriate for gestational age (68 females, 64 males), gestational age between 35-42 weeks. Data were collected through interviews with the mothers at the maternity, anthropometrycal study of the newborns, and cord blood estradiol, testosterone and leptin assays obtained immediately after birth.

Results: The levels of leptin were significantly higher in females than in males $(8.34 \pm 0.65 \mathrm{ng} / \mathrm{ml}$ versus $6.06 \pm 0.71 \mathrm{ng} / \mathrm{ml} ; \mathrm{p}=0.000)$. The concentrations of estradiol and testosterone did not differ between males and females. Leptin levels were positively correlated with gestational age $(r=0.394, p<0.01)$, birth weight $(r=0.466, p<0.01)$, birth length $(r=0.335, p<0.01)$ and ponderal index $(r=0.326$, $\mathrm{p}<0.01)$.

Conclusions: Leptin concentration in the umbilical cord is positively correlated with gestational age, birth weight, birth height, and ponderal index, suggesting its participation in the neonatal growth process. In addition, a gender difference with higher levels of leptin in females neonates was observed, suggesting that the sexual dimorphism in relation to body composition already exists in newborns.
\end{abstract} growth

J Pediatr (Rio J). 2004;80(4):305-8: Leptin, newborn, birth weight,

Estudos em ratos revelaram que a leptina apresenta papel importante na função neuroendócrina. A mutação do gene $o b / o b$, que codifica a leptina em ratas, provoca infertilidade, ausência de desenvolvimento puberal, obesidade e resistência à insulina ${ }^{1}$.

Nos seres humanos, a leptina tem sido correlacionada com a massa gorda corpórea e o balanço energético, além de apresentar variações conforme o sexo e o desenvolvimento puberal 2,3 .

Em 1997, descobriu-se que a leptina é produzida também pela placenta e pelo feto ${ }^{4,5}$. Isso desencadeou a realização de estudos que investigam a relação da leptina com o crescimento fetal e também como indicadora dos depósitos de energia do recém-nascido através de sua dosagem no sangue do cordão umbilical. No Brasil, há carência de estudos que avaliem as concentrações de leptina no cordão umbilical, bem como sua variabilidade conforme o sexo dos recém-nascidos. 
O objetivo deste estudo é avaliar os níveis de leptina do cordão umbilical em recém-nascidos adequados para a idade gestacional conforme sexo, peso, comprimento e índice ponderal de nascimento.

\section{Material e métodos}

Foi realizado um estudo epidemiológico tipo transversal por meio da avaliação de 132 recém-nascidos adequados para a idade gestacional ( 68 do sexo feminino, 64 do sexo masculino), com idade gestacional de 35-42 semanas, nascidos no centro obstétrico do Hospital Regional de Sorocaba durante o período de janeiro de 2001 a fevereiro de 2002. Foram selecionados para o estudo apenas os nascidos durante o período diurno (entre 7 e 16 horas), pois há referências na literatura sobre a variação nos níveis de leptina durante o período noturno ${ }^{6}$.

O cálculo do tamanho amostral foi determinado com base na ocorrência prévia relatada por Koistinen et al. em $1997^{4}$, sendo 96 o número mínimo de amostras necessárias para este estudo. Os valores de $\alpha$ e $\beta$ admitidos para este cálculo foram de 0,05 e 0,10, respectivamente.

Os recém-nascidos foram selecionados segundo os seguintes critérios: idade gestacional entre 35-42 semanas, adequados para a idade gestacional, recém-nascidos prematuros cujas gestantes não fizeram uso de corticoterapia, Apgar de primeiro minuto igual ou superior a 7, ausência de malformações congênitas, parto não-gemelar, ausência de enfermidades maternas como hipertensão arterial, diabetes melito, doenças da tireóide ou hipercolesterolemia.

Foram excluídos todos os recém-nascidos de mães tabagistas ou etilistas durante a gravidez.

O estudo foi realizado em duas etapas:

$1^{\text {a }}$ etapa: preenchimento de questionário com dados maternos, coleta do sangue do cordão umbilical, avaliação do recém-nascido.

$2^{a}$ etapa: dosagens laboratoriais.

Na primeira fase do estudo, foi preenchido pelo pesquisador um questionário materno, previamente testado, cuja meta era a obtenção de dados clínicos sobre a gestação. Ainda na primeira fase do estudo, foram obtidos os dados referentes ao recém-nascido: peso e comprimento ao nascer, índice ponderal, sexo, Apgar, idade gestacional e peso da placenta. Os recém-nascidos foram pesados utilizandose uma balança microeletrônica portátil e medidos através de um antropômetro apropriado. Duas medidas foram realizadas e comparadas; quando essas medidas diferiram, utilizou-se a média entre as mesmas. $O$ índice ponderal corresponde ao peso do recém-nascido em gramas, dividido pelo comprimento em centímetros ao cubo, multiplicado por 100. A idade gestacional foi calculada pela data da última menstruação e confirmada pela ultra-sonografia.

Os recém-nascidos foram classificados quanto à adequação do peso à idade gestacional de acordo com a curva de Alexander et al. ${ }^{7}$; após, selecionou-se apenas os recémnascidos adequados para a idade gestacional.
A segunda etapa do estudo compreendeu as dosagens laboratoriais. A leptina foi obtida do sangue venoso do cordão umbilical, coletado imediatamente após o nascimento, não tendo ocorrido contaminação com o sangue materno, sendo centrifugado e congelado até a análise simultânea de todo o material. Todos os casos em que ocorreu ruptura da placenta foram excluídos do estudo. A leptina foi medida por radioimunoensaio (Linco Research, St. Charles, Missouri, EUA). A concentração mínima detectável de leptina foi de $0,5 \mathrm{ng} / \mathrm{ml}$, com coeficientes de variação intra- e interensaios inferiores a 3 e $6 \%$, respectivamente. O estradiol e a testosterona foram dosados por técnica de radioimunoensaio (Diagnostic Systems Laboratories, Texas, USA). A concentração mínima detectável de estradiol foi de $0,01 \mathrm{ng} / \mathrm{ml}$, e a de testosterona foi de $0,08 \mathrm{ng} / \mathrm{ml}$. Os coeficientes de variação intra- e interensaios para estradiol e testosterona foram inferiores a $5 \%$.

Este estudo foi realizado de acordo com a revisão atual da Declaração de Helsinque e com a Resolução Brasileira 196, de 10 de outubro de 1996, sendo aprovado antes de seu início pelo Comitê de Ética local.

Para a análise dos dados, foram calculadas as médias e os respectivos erros padrão das médias ou mediana e variação, e verificadas as diferenças pelo teste nãoparamétrico Mann-Whitney e teste de qui-quadrado para variáveis categóricas. Foi utilizado o coeficiente de Spearman para o cálculo das correlações e adotado $\mathrm{p}<$ 0,05 como valor significativo. O programa SPSS versão 7.5 foi utilizado para todos os cálculos estatísticos.

\section{Resultados}

As características clínicas dos recém-nascidos estão resumidas na Tabela 1 . A idade gestacional média dos recém-nascidos foi de 38,58 semanas, com peso médio de $3.053 \mathrm{~g}$, comprimento médio de $47,78 \mathrm{~cm}$, índice ponderal médio de 2,79 e peso da placenta com média de 539,96 g. Existiam 10 prematuros no grupo do sexo feminino e 12 prematuros no grupo masculino $(p=0,728)$. Não houve diferenças significativas quanto ao sexo desses dados.

Os escores de Apgar de 1 e 5 minutos não diferiram estatisticamente entre os sexos. Tanto no grupo feminino quanto no masculino a mediana do Apgar de 1 minuto foi 8 (variação 7-9) e de 5 minutos foi 9 (variação 9-10).

Recém-nascidos do sexo feminino possuem níveis de leptina significativamente maiores $(p=0,000)$ que os do sexo masculino $(8,34 \pm 0,65 \mathrm{ng} / \mathrm{ml}$ versus $6,06 \pm 0,71 \mathrm{ng} / \mathrm{ml})$. As concentrações séricas dos hormônios sexuais, estradiol e testosterona, não apresentaram variações entre recémnascidos do sexo masculino e feminino (Tabela 1 ).

A leptina do cordão umbilical se correlacionou com parâmetros antropométricos dos recém-nascidos, conforme descrito na Tabela 2. A idade gestacional e o peso de nascimento apresentaram moderado grau de associação com a leptina sérica $(p<0,01)$. A leptina do cordão umbilical também se correlacionou em menor grau com o comprimento e com o índice ponderal do recém-nascido $(p<0,05)$. 
Tabela 1 - Características dos recém-nascidos e dosagens de estradiol, testosterona e leptina conforme o sexo

\begin{tabular}{lccc}
\hline Sexo & Masculino $(\mathbf{n}=\mathbf{6 4})$ & Feminino $(\mathbf{n}=\mathbf{6 8})$ & Total $(\mathbf{n}=\mathbf{1 3 2})$ \\
\hline Idade gestacional (semanas) & $38,51 \pm 0,23$ & $38,64 \pm 0,22$ & $38,58 \pm 0,16$ \\
Peso de nascimento (g) & $3.074 \pm 50,45$ & $3.033 \pm 51,77$ & $3.053 \pm 36,09$ \\
Comprimento (cm) & $47,95 \pm 0,24$ & $47,61 \pm 0,30$ & $47,78 \pm 0,19$ \\
Índice ponderal & $2,78 \pm 0,03$ & $2,80 \pm 0,03$ & $2,79 \pm 0,02$ \\
Peso da placenta (g) & $546,25 \pm 13,35$ & $534,04 \pm 12,51$ & $539,96 \pm 9,12$ \\
Estradiol (ng/ml) & $9,17 \pm 0,50$ & $9,53 \pm 0,45$ & $9,48 \pm 0,29$ \\
Testosterona (ng/ml) & $3,45 \pm 0,24$ & $4,23 \pm 0,38$ & $4,12 \pm 0,22$ \\
Leptina $(\mathrm{ng} / \mathrm{ml})$ & $6,06 \pm 0,71$ & $8,34 \pm 0,65 *$ & $7,23 \pm 0,49$ \\
\hline
\end{tabular}

Dados expressos em média e erro padrão da média.

* $\mathrm{p}=0,000$ versus sexo masculino.

Tabela 2 - Correlações entre leptina do cordão umbilical e parâmetros antropométricos dos recém-nascidos

Recém-nascidos

Total $(n=132)$

Leptina versus

idade gestacional do recém-nascido

$0,394^{*}$

Leptina versus

peso de nascimento do recém-nascido

$0,466 *$

Leptina versus

comprimento ao nascer do recém-nascido

$0,335^{*}$

Leptina versus

índice ponderal do recém-nascido

$0,326 *$

Leptina versus peso da placenta

0,103

Coeficiente de correlação de Spearman * $p<0,01$.

\section{Discussão}

Este estudo demonstrou que as concentrações de leptina do cordão umbilical se correlacionam com parâmetros antropométricos neonatais e que os recém-nascidos do sexo feminino apresentam níveis superiores de leptina quando comparados aos do sexo masculino. Uma vez que este estudo apresentou um número de recém-nascidos similar conforme o sexo e não encontrou diferenças quanto ao índice ponderal, peso, comprimento e hormônios sexuais entre neonatos do sexo masculino e feminino, sugere-se, pela primeira vez, que este dimorfismo quanto à composição corporal esteja associado ao maior depósito de gordura subcutânea existente no sexo feminino.

O crescimento fetal é caracterizado por uma fase inicial de organização e diferenciação tecidual, associada a uma intensa proliferação celular. Fatores genéticos, suprimento transplacentário de oxigênio e de substratos, além das ações endócrina e parácrina de hormônios produzidos pelo feto, placenta ou mãe, são os principais moduladores do crescimento fetal ${ }^{8}$.

O controle hormonal do crescimento fetal é exercido por hormônios de origem placentária ou de origem fetal. A regulação pode ser indireta, por modular o crescimento e fluxo sangüíneo placentário, ou direta, pela transferência de hormônio placentário ao feto. Entre esses hormônios estão: GH fetal, insulina, somatomedina, hormônios tireoidianos e esteróides sexuais ${ }^{9}$. Estudos recentes sugerem que a leptina também esteja envolvida nesse processo10-11.

A leptina pode ser dosada tanto no fluido amniótico quanto no cordão umbilical a partir de 25 semanas de gestação ${ }^{5}$. Enquanto a leptina proveniente do líquido amniótico reflete o ambiente materno, a leptina do cordão é derivada tanto da placenta como do tecido fetal. Assim, a maioria dos estudos publicados até o momento são unânimes ao afirmar que a leptina dosada no sangue materno se correlaciona apenas com a adiposidade maternal ${ }^{12-14}$.

A presença de leptina no sangue do cordão umbilical humano tem sido demonstrada em diversos estudos. Este estudo demonstrou uma correlação positiva entre leptina do cordão umbilical e idade gestacional, peso, comprimento e índice ponderal dos recém-nascidos. Esse achado é semeIhante ao encontrado em estudos prévios, sugerindo que a produção de leptina no cordão esteja relacionada com o desenvolvimento do tecido adiposo fetal. Koistinen et al. ${ }^{4}$ encontraram associação positiva entre crescimento fetal e concentração de leptina no cordão umbilical. Matsuda et al. ${ }^{15}$ realizaram um estudo com 82 recém-nascidos, com idade gestacional entre 36-42 semanas e peso de nascimento entre 2.306-4.128 g, e encontraram associação positiva entre peso de nascimento e leptina no cordão umbilical. Helland ${ }^{16}$ também descreveu essa mesma associação em seu estudo publicado em 1997.

Há controvérsias na literatura mundial quanto a uma possível correlação entre leptina do cordão umbilical e peso da placenta, existindo estudos que encontraram tal associação17-18, enquanto outros não encontraram ${ }^{19-20}$. Este estudo não encontrou uma correlação entre leptina e peso da placenta.

Recentemente, novos estudos têm sido publicados, confirmando a importância da leptina no crescimento fetal. Estudo publicado em 2000 verificou que a leptina do cordão umbilical se correlaciona negativamente com ICTP 
(carboxy-terminal telopeptide type I collagen), que é um marcador de reabsorção óssea, sugerindo que a leptina provavelmente diminui a reabsorção óssea, com conseqüente aumento da massa óssea ${ }^{21}$. Christou et al. 22 observaram que o peso ao nascer apresenta uma associação independente dos níveis de IGF-I com as concentrações de leptina do cordão, sugerindo que a leptina esteja envolvida em mecanismos ainda desconhecidos de regulação do crescimento fetal.

Embora a diferença nas concentrações de leptina em adultos segundo o sexo seja bem documentada, em crianças e recém-nascidos existem poucos estudos ${ }^{23-24}$. Este estudo demonstrou que os recém-nascidos do sexo feminino apresentaram níveis séricos de leptina maiores que os do sexo masculino. Observamos que esta diferença existe mesmo quando comparamos recém-nascidos do sexo masculino e feminino com as mesmas características quanto ao peso, comprimento e índice ponderal. Resultado semelhante foi encontrado num estudo de coorte realizado com 197 recém-nascidos na Inglaterra, publicado em 199925, que demonstrou que os recém-nascidos do sexo feminino têm níveis maiores de leptina que os do sexo masculino, independentemente do tamanho de nascimento. Isso sugere que provavelmente o dimorfismo sexual relacionado à composição corporal já exista em recém-nascidos.

Os mecanismos envolvidos nas variações dos níveis de leptina conforme o sexo dos neonatos ainda são desconhecidos. Verificou-se neste estudo que as concentrações dos hormônios sexuais no cordão umbilical são similares quanto ao sexo. Deste modo, os hormônios sexuais no cordão umbilical não devem interferir na variabilidade da leptina quanto ao sexo. Este estudo sugere que provavelmente as diferenças quanto aos depósitos de gordura subcutânea conforme o sexo possam explicar essa diferença entre leptina dosada em recém-nascidos do sexo masculino e feminino. Estudo prévio ${ }^{26}$ relata que o índice ponderal não é um bom indicador dos depósitos gordurosos do recémnascido, sendo que a medida das pregas cutâneas do sexo feminino é superior comparada à do sexo masculino. Estudos futuros utilizando métodos de bioimpedância poderão esclarecer as razões dessas diferenças e suas associações com o crescimento do recém-nascido.

Em conclusão, nosso estudo encontrou uma correlação positiva da leptina do cordão umbilical com a idade gestacional, peso, comprimento e índice ponderal do recém-nascido, sugerindo sua associação com o processo de crescimento neonatal. Concluímos também que os recém-nascidos do sexo feminino têm níveis séricos de leptina maiores que os do sexo masculino, sugerindo que o dimorfismo sexual relacionado à composição corporal já possa existir em neonatos.

\section{Agradecimentos}

Agradecemos à biomédica Sandra Grandin Pereira, do Departamento de Endocrinologia da UNICAMP, pela sua valiosa colaboração na realização da dosagem da leptina. Agradecemos também à FAPESP, pelo financiamento do projeto.

\section{Referências}

1. Zhang $Y$, Proenca $R$, Maffei M, Barone M, Leopold L, Friedman J. Positional cloning of the mouse obese gene and its human homologue. Nature. 1994;372:425-32.

2. Seeley RJ, Schwartz MW. Neuroendocrine regulation of food intake. Acta Paediatr Suppl. 1999;88(428):58-61.

3. Cunningham MJ, Clifton DK, Steiner RA. Leptin's actions on the reproductive axis: perspectives and mechanisms. Biol Reprod. 1999;60:216-22.

4. Koistinen HA, Koivisto VA, Kontula K, Andersson S, Teramo KA, et al. Leptin concentration in cord blood correlates with intrauterine growth. J Clin Endocrinol Metab. 1997;82:3328-30.

5. Schubring C, Kiess W, Englaro P, Rascher W, Dotsch J, Blum W, et al. Levels of leptin in maternal serum, amniotic fluid, and arterial and venous cord blood: relation to neonatal and placental weight. J Clin Endocrinol Metab. 1997;82:1480-3.

6. Tarquini B, Tarquini R, Perfetto F, Cornelissen G, Halberg F. Genetic and environmental influences on human cord blood leptin concentration. Pediatrics. 1999;103:998-1006.

7. Alexander GR, Himes JH, Kaufman RB, Mor J, Kogan M. A United States National Reference for fetal growth. Obstet Gynecol. 1996;87:163-8.

8. Monte O, Longui CA, Calliari LEP. Endocrinologia Pediátrica. São Paulo: Editora Atheneu; 1998.

9. van den Brandle JL. Somatomedins on the move. Horm Res. 1990; 33:58-68.

10. Gómez L, Carrascosa A, Yeste D, Potau N, Riqué S, Almar J, et al. Leptin values in placental cord blood of human newborns with normal intrauterine growth after 30-42 weeks of gestation. Horm Res. 1999;51:10-14.

11. Vatten LJ, Nilsen ST, Odegård RA, Romundstad PR, Austgulen R. Insulin-like growth factor I and leptin in umbilical cord plasma and infant birth size at term. Pediatrics. 2002;109:1131-5.

12. Hassink SG, Lancey E, Sheslow DV, Considine RV, Dostal K, SmithKirwin SM, et al. Placental leptin: important new growth factor in intrauterine and neonatal development? Pediatrics. 1997;100:E1.

13. Tamura T, Goldenberg RL, Johnston KE, Cliver SP. Serum leptin concentrations during pregnancy and their relationship to fetal growth. Obstet Gynecol. 1998;91:389-95.

14. Schubring C, Englaro P, Siebler T, Blum WF, Demirakca T, Kiess W, et al. Longitudinal analysis of maternal serum leptin levels during pregnancy, at birth and up to six weeks after birth: relation to body mass index, skinfolds, sex steroids and umbilical blood leptin levels. Horm Res. 1998; 50:276-83.

15. Matsuda J, Yokota I, Iiida M, Murakami T, Naito E, Ito M, et al. Serum leptin concentration in cord blood: relationship to birth weight and gender. J Clin Endocrinol Metab. 1997;82:1642-4.

16. Helland IB, Reseland JE, Saugstad OD, Drevon CA. Leptin levels in pregnant women and newborn infants: gender differences and reduction during the neonatal period. Pediatrics. 1998;101:E12.

17. Geary M, Pringle PJ, Persaud M, Wilshin J, Hindmarsh PC, Rodeck CH, et al. Leptin concentrations in maternal serum and cord blood: relationship to maternal anthropometry and fetal growth. $\mathrm{Br}$ J Obstet Gynaecol. 1999;106:1054-60.

18. Schulz S, Häckel C, Weise W. Hormonal regulation of neonatal weight: placental leptin and leptin receptors. BJOG. 2000;107: 1486-91.

19. Lepercq J, Lahlou N, Timsit J, Girard J, Mouzon SH. Macrosomia revisited: ponderal index and leptin delineate subtypes of fetal overgrowth. Am J Obstet Gynecol. 1999;181:621-5.

20. Papadopoulou FG, Mamopoulos AM, Triantos A, Constantinidis TC, Papadimas J, Assimakopoulos EA, et al. Leptin levels in maternal and cord serum: relationship with fetal development and placental weight. J Matern Fetal Med. 2000;9:298-302.

21. Ogueh $\mathrm{O}$, Sooranna $\mathrm{S}$, Nicolaides $\mathrm{KH}$, Johnson MR. The relationship between leptin concentration and bone metabolism in the human fetus. J Clin Endocrinol Metab. 2000;85:1997-9.

22. Christou H, Connors JM, Ziotopoulou M, Hatzidakis V, Papathanassoglou $E$, Ringer $S A$, et al. Cord blood leptin and insulin-like growth factor levels are independent predictors of fetal growth. J Clin Endocrinol Metab. 2001;86:935-8.

23. Su PH, Wang SL, Chen JY, Lai CP, Jian SH. Serum leptin levels in preterm, healthy and sick-term newborns. Acta Paediatr Taiwan. 2002;43:249-54.

24. Yang MJ, Liu RS, Hung JH. Leptin concentrations in the umbilical vein and artery. Relationship to maternal and neonatal anthropometry. J Reprod Med. 2002;47:645-50.

25. Ong KK, Ahmed ML, Sherriff A, Woods KA, Watts A, Golding J, et al. Cord blood leptin is associated with size at birth and predicts infancy weight gain in humans. J Clin Endocrinol Metab. 1999;84:1145-8.

26. Copper RL, Goldenberg RL, Cliver SP, Dubard MB, Hoffman HJ, Davis RO. Anthropometric assessment of body size differences of full-term male and female infants. Obstet Gynecol. 1993;81:161-4.

Correspondência:

Inês M. C. G. Pardo

Rua Souza Pereira, 138 - CEP 18010-320 - Sorocaba, SP

Fone: (15) 232.4699 - Fax: (15) 232.7050

E-mail: doctorpardo@hotmail.com; loli@terra.com.br 